\title{
A Escravidão Numa Área de Pastoreio: os "Campos" de Lages
}

Walter F. Piazza

Os "Campos" de Lages

O Território catarinense é dividido, geomorfologicamente, em litoral e planalto (vide mapa).

Neste planalto predominantemente basáltico há áreas sedimentares, como aquela em que se situa a cidade de Lages e os seus arredores.

A este planalto deu-se a denominação ampla de "campos" de Lages, porquanto, jurisdicionalmente todo ele era centralizado por aquela cidade.

Para caracterizar a sua cobertura vegetal tem-se esta descrição:

"No planalto de Lages dá-se o contato das matas costeiras com os pinhais, a produzir associações mistas, matas sub-xer6filas, chamadas faxinais. Os campos sem árvores - campinas - são raras, porque o campo, quase sempre, se apresenta como savanas de araucária, ou como 'vassourais' que lembram os campos cerrados, dos quais se destacam, tanto pelas espécies arbóreas que os formam, como pelo fato de sua destruição periódica pelo fogo e conseqüente retorno a campina."

Neste ambiente, Antonio Correia Pinto, com sua bandeira povoadora, integrada por parentes e associados, a mando de D. Luis Antônio de Sousa Botelho Mourão, Morgado de Mateus, então Gover- 
nador e Capitão-General de São Paulo, funda a povoação de Nossa Senhora dos Prazeres das Lagens, em 1771. ${ }^{2}$

\section{AS GRANDES REGIÕES}

\section{SERRAS NA BORDA DO PLANALTO}

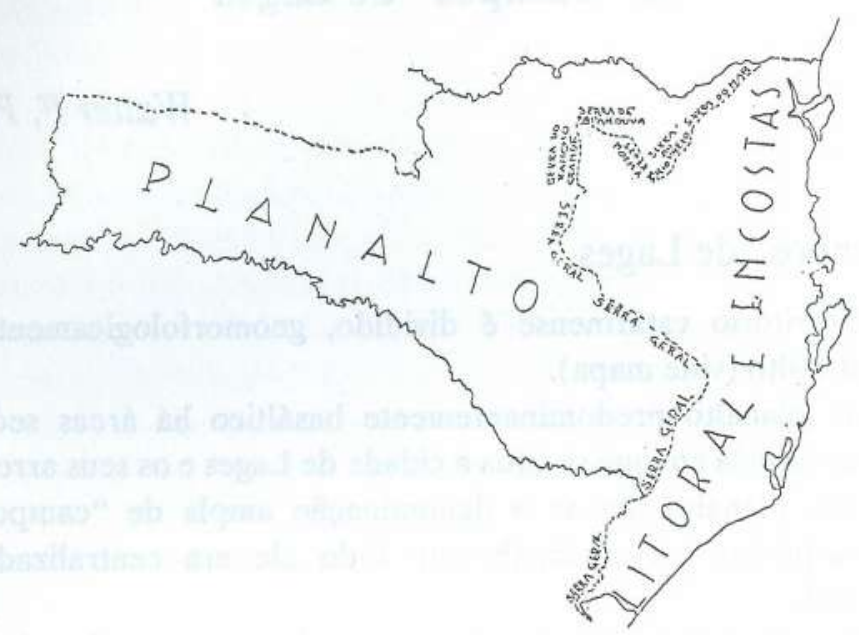

PELUSO JR, Victor A. O relevo do Estado de Santa Catarina. Florianópolis, DEGC, 1952.

Esta fundação se faz por várias razões. Em primeiro lugar era mais um posto avançado lusitano nos ínvios sertões, dentro do quadro conflitante entre as coroas ibéricas, na América do Sul, garantindo a única via de São Paulo para os campos de Viamão, em qualquer emergência. Por outro lado, consolidava a abertura do "caminho dos Conventos" ou "caminho do Sul", efetuada por Francisco de Sousa e Faria, em 1730, ao longo do qual se instalaram várias fazendas de criação-de-gado (onde Correia Pinto já possuía uma), o que era um fator econômico e que, por si s6, seria suficiente para provocar o povoamento da região e determinar a existência do povoado.

E, por último, era um núcleo social, que desafogava o latifúndio paulista, transferindo-o para o planalto catarinense, com os índios mansos e agregados, além dos escravos, submetidos ao regime senhorial, "de baraço e cutelo", do fazendeiro. Era mais uma "ilha" humana, no imenso Brasil-Meridional. ${ }^{3}$ 


\section{Os "Censos de Ordenanças" e a escravatura}

Anteriormente não se fizeram estudos específicos sobre as condições da escravidão nesta área de pastoreio, mas, tão-somente, divulgaram-se informações esparsas ${ }^{4}$, razão porque se pretende, aqui, ainda que, com dados fragmentários, mostrar como se desenvolveu aquele regime de trabalho, na região em foco.

O Morgado de Mateus, Dom Luís Antônio de Sousa Botelho Mourão (1722-1796), em cujo Governo na Capitania de São Paulo (1765-1775), ${ }^{5}$ fez realizar "Censos de Ordenanças", que mereceram esta análise: ${ }^{6}$

"Através dos numerosos Censos das Ordenanças da Capitania de São Paulo, iniciados nesse ano (1776 ou 1767), pelo Morgado de Mateus e continuados pelos sucessores desse bem avisado Governador de S. Paulo, podemos hoje saber a relação dos povos da Nova Povoação da Vila de Nossa Senhora dos Prazeres das Lages, nos anos de 1776, 1777, 1789, 1790, 1792 e 1794. Os dois primeiros feitos ainda pelo fundador da Vila, Antonio Correa Pinto, o de 89 pelo Capitão de Ordenanças Manoel Rodrigues de Ataíde e os restantes pelo CapitãoMor regente Bento do Amaral Gurgel Anes, Joaquim José Monteiro, Sargento-Mor das Ordenanças, Joanes Anes do Amaral Gurgel, Ajudante das Ordenanças".

Em função desses "Censos das Ordenanças" pode-se, hoje, verificar o contingente de escravos de cada um dos proprietários de fazendas-de-criação de gado, nos campos de Lages.

A partir dos referidos "Censos", elaborou-se a tabela, onde se acompanhou, através das listas nominativas, a persistência da propriedade de escravos, no período 1777 a 1803.

Deixou-se, na aludida tabela, de incluir aqueles que, no ano de 1803, possuiam um ou dois escravos e não estavam listados nos anteriores "Censos de Ordenanças".?

Tendo como apoio pesquisas documentais, ${ }^{8}$ procura-se definir a relação entre a propriedade rural, do latifúndio de pecuária extensiva e a escravidão. (V. tabela "Campos de Lages - proprietários e escravos".) 
Campos de Lages - Proprietários e Escravos

\begin{tabular}{|c|c|c|c|c|c|c|}
\hline \multirow{2}{*}{$\begin{array}{l}\text { Nome dos } \\
\text { Proprietários }\end{array}$} & \multicolumn{6}{|c|}{ Número de Escravos } \\
\hline & 1777 & 1789 & 1790 & 1792 & 1794 & 1803 \\
\hline Antonio C. Pinto & 30 & - & - & - & - & - \\
\hline Bento do Amaral Gurgel Anes & - & 11 & 10 & 8 & 14 & 4 \\
\hline Baltazar Joaquim đe Oliveira & - & 2 & 2 & 1 & 1 & 2 \\
\hline Antonio Roiz Fam de Oliveira & - & 7 & 2 & 2 & 4 & - \\
\hline Joaquim José Monteiro & - & 14 & 13 & 14 & - & - \\
\hline Manoel Roiz de Ataide & - & 1 & 1 & 1 & 1 & - \\
\hline Padro da Silva Ribeiro & - & 7 & 6 & 7 & 7 & 3 \\
\hline Antonio Marques Arzão & - & 1 & 1 & 3 & 3 & - \\
\hline João Damasceno de Cordova & - & 4 & 5 & 8 & 9 & 7 \\
\hline Manoel da Silva Ribeiro & - & 2 & 2 & 2 & - & - \\
\hline Jose Joaquim Leme (do Prado) & - & 8 & 8 & - & - & - \\
\hline Joaquim José Pereira & - & - & 20 & 31 & 29 & 41 \\
\hline Bento Soares da Mota & - & - & 1 & 2 & 3 & - \\
\hline Manoel de Araujo Gomes & - & - & 8 & 8 & 10 & - \\
\hline Bernardino da Costa Filgueiras & - & - & 4 & 3 & 1 & - \\
\hline Miguel Bicudo (do Amarante) & - & - & - & 2 & - & 3 \\
\hline Manoel Teixeira de Oliveira Car & oso- & - & - & 4 & - & - \\
\hline José Martins Ferraz & - & - & - & 3 & 6 & - \\
\hline José Antônio de Lacerda & - & - & - & 8 & 7 & - \\
\hline Belchior de Arantes & - & - & - & 2 & 2 & 4 \\
\hline Miguel Pedroso Leite & - & - & - & - & 4 & - \\
\hline D. Barbara Garcia & - & - & - & - & 16 & - \\
\hline Antonio de A. França & - & - & - & - & 1 & 2 \\
\hline Manoel de Barros & - & - & - & - & 4 & - \\
\hline Antonio de P. (Correa) & - & - & - & - & 3 & 5 \\
\hline Andre Guerreiro & - & - & - & - & - & 7 \\
\hline
\end{tabular}

Assim, o fundador de Lages, Antonio Correa Pinto (ca. 1719-1783), foi proprietário de duas fazendas, antes mesmo de erigir aquela vila: "Cruz de Malta" e "Guarda-mor".

Bento do Amaral Gurgel Anes, natural de Taubaté, casado com uma irmã de Bento Soares da Mota (vide), em primeiras núpcias, de quem recebeu, por doação, uma fazenda "na paragem chamada das Tijucas", que vendeu (1774) a João da Costa Moreira, e adquiriu, por sua vez, da viúva de Antônio Correa Pinto as fazendas "Cruz de Malta" e "Guarda-mor".

Baltazar Joaquim de Oliveira, cunhado de Correa Pinto, foi proprietário da fazenda "Ronda Grande", no "passo do Rio Caveiras", 
que vendeu a Hipólito Machado Dias (1843), que, por sua vez, a vendeu (1853) a Generoso Pereira dos Anjos Júnior.

Antonio Roiz (Rodrigues) Fam de Oliveira, também cunhado de Correa Pinto, comprou fazenda de Manoel José de Novaes (1807).

Joaquim José Monteiro foi, inicialmente, capataz de Antônio Correa Pinto, e por ocasião da contrução da Igreja Matriz de Lages doou dez potros como esmola àquela obra. Foi proprietário da fazenda "Sorocaba", anexa à do "Rincão".

Manoel Roiz (Rodrigues) de Ataíde chega aos campos de Lages juntamente com Correa Pinto. Foi proprietário de uma fazenda "na paragem xamada Ilha", que vendeu a Jacinto de Araujo Nóbrega (1783).

Pedro da Silva Ribeiro, filho de Manoel da Silva Ribeiro (vide), vindo de Viamão, já era morador em Lages, em 1771, tendo fazenda "na paragem das Tijucas" e possuiu, posteriormente (1817), a fazenda "Pelotinhas", juntamente com Salvador Nunes, "no distrito da Costa da Serra".

Antônio Marques Arzão chega à vila de Lages, após a fundação (1771), sendo proprietário da fazenda "Faxinal", "na costa do rio Pelotas". que vendeu a Mateus José de Sousa (1775).

João Damasceno de Córdova, natural de Santos, chega à região de Lages, aproximadamente em 1775, possuindo uma fazenda em Lages e outra em Vacaria. No Censo das Fazendas que se realizou em 1801, assinala a existência de 24 , apenas!

Manoel da Silva Ribeiro, morador em Lages (1771), para onde se mudou com seus filhos Pedro (vide) e Inácio.

José Joaquim Leme (do Prado) se teve fazenda, não se obteve a sua localização.

Joaquim José Pereira foi proprietário (1803) das fazendas "São Luis", "Morro Agudo" e "Pedras Brancas".

Bento Soares da Mota, considerado o precursor da fundação de fazendas na região lageana, após a abertura do "caminho do sul", foi dono de várias delas e doou a fazenda "Tijucas" a Bento do Amaral Gurgel Anes (vide).

Manoel de Araujo Gomes, já, em 1775, era proprietário de terras.

Bernardino da Costa Filgueiras teve fazenda "nos Indios", sesmaria concedida a 30.10 .1790 . 
Miguel Bicudo do Amarante era proprietário de pequena fazenda "na Costa da Serra", que adquiriu da viúva de Manoel de Barros (vide), em 1811.

Manoel Teixeira de Oliveira Cardoso teve uma sesmaria concedida a 08.03.1790 "nos fins do Potreiro Grande e Potreiro de Nossa Senhora", que divide os "campos do Serito" e "desaguam no rio Caveiras".

José Martins Ferraz, não aparece como proprietário de fazenda.

José Antônio de Lacerda. identicamente.

Belchior de Arantes vendeu, em 1788, parte de sua fazenda, "na barra do rio Pelotinhas", a Agostinho Alves Garcia, e que, anteriormente pertencera a Aleixo Leme do Prado.

Miguel Pedroso Leite, já reside em Lages, em 1790, mas não se teve referência à propriedades suas.

D. Bárbara Garcia é a viáva de Joaquim José Monteiro (vide).

Antônio de Araújo França foi escrivão da Câmara e não se tem registros de ter possuído fazenda.

Manoel de Barros possuia sesmaria concedida a 27.01.1779, "nas cabeceiras do rio Pelotas e do rio Lavatudo", e, em 1796, a fazenda "Santo Antônio da Costa Serra" e uns campos chamados "Taipas", em sociedade com Joaquim Rodrigues dos Santos.

Antônio de Pontes Corrêa possuía, em 1817, a fazenda "Pedras Brancas", que pertencera, anteriormente, a Joaquim José Pereira (vide).

E, André Guerreiro, de quem não se obteve registro, como proprietário de fazenda.

Assim, procurou-se correlacionar a propriedade pastoril com a posse de escravos.

Pelo quadro sumário vê-se que o crescimento da população escrava não é tão significativa.

De 114 em 1777 alcança, em 1808, um total de 155, enquanto a população livre triplica.

Além dos escravos, tem-se os "índios mansos" e os agregados, sujeitos ao "fazendeiro", como estão anotados nas "listas nominativas" dos "Censos de Ordenanças" e, especialmente, no de 1803, há grande quantidade de agregados de cor! 
Lages - Quadro sumário "Censos de Ordenanças"

\begin{tabular}{lcccc}
\hline \multirow{2}{*}{ Anos } & \multicolumn{5}{c}{ Populacăo } \\
\cline { 2 - 5 } & Brancos & Livres & Escravos & TOTAL \\
\hline 1777 & - & 257 & 114 & 371 \\
1778 & 347 & 94 & 181 & 622 \\
1789 & - & - & - & 570 \\
1790 & - & - & - & 550 \\
1792 & - & - & - & 685 \\
1794 & - & - & - & 829 \\
1798 & - & 460 & 138 & 598 \\
1808 & - & 723 & 155 & 878 \\
\hline
\end{tabular}

\section{A escravidão e a propriedade territorial: outra fase}

Os dados estatísticos que se tem obtido em estimativas efetuadas, quer por viajantes, quer pela administração pública, embaraçam o analista!

Para o período 1840-1872, que é do máximo interesse para a nossa análise, os números absolutos obtidos, quanto à escravidão na região dos "Campos de Lages", não são, também isentos de erros (v. LAGES ESCRAVIDÃO - 1840 a 1872). ${ }^{9}$

$$
\text { Lages - Escravidão, 1840-1872 }
$$

\begin{tabular}{cc}
\hline Anos & Número de Escravos \\
\hline 1849 & $1.000^{*}$ \\
1856 & 1.195 \\
1872 & 2.012 \\
\hline
\end{tabular}

- Estimativa.

FONTES = 1840, Van Lede; 1856, Aubé; 1872, Recenseamento Geral do Império.

Entretanto, para este período procurou-se, através de uma conjunção de dados, visualizar a problemática da relação da propriedade da terra com a propriedade de escravos. 
Utilizou-se para conhecimento da propriedade rural os "Registros de Vigários" - declaração dos proprietários de terras perante o vigário de sua freguesia (paróquia) sobre o tamanho e as confrontações de suas propriedades, em cumprimento ao estabelecido na Lei $\mathrm{n}^{2} 601$, de 18.09.1850, regulamentada pelo Decreto $n^{2} 1.318$, de $30.01 .1854^{10} \mathrm{e}$, para conhecimento dos escravos, utilizou-se os registros eclesiásticos da freguesia de N. Sra. dos Prazeres das Lages, relativas aos eventos vitais (batizados e óbitos). ${ }^{11}$

Os dados obtidos nos oferecem algumas reflexões e que se farão à vista da tabela seguinte (v. LAGES - PROPRIEDADES LEGITIMADAS E ESCRAVOS) ${ }^{12}$

Tem-se 111 (cento e onze) proprietários de escravos que possuem propriedades territoriais legitimadas, face à "Lei de Terras", enquanto, de outra parte, se tem 391 senhores de escravos sem propriedades de terras.

Dos dados coletados, tem-se:

a) com relação aos registros de batismo constatou-se que a maioria dos batizados são escravos nascidos no Brasil, e, somente, nos registros de óbitos é que se assinala, naqueles de mais idade, a proveniência africana (pelo menos 14!);

b) anota-se também, o registro de "bugres" como escravos (estes em número de nove!);

c) há, aparentemente, a existência de escravas reprodutoras, para alguns proprietários, dada a constância periódica de nascimentos havidos dessas escravas.

Lages - Propriedades Legitimadas e Escravos

\begin{tabular}{|c|c|c|}
\hline Proprietário & $N^{\bullet}$ Escravos & Tamanho Propriedade \\
\hline Atanásio José de Oliveira & 5 & $11 / 2$ legua de frente $x 2$ de fundos \\
\hline Antônio do Amaral Gurgel & 21 & $1 / 4$ de légua de frente $\times 1 / 4$ de fundos \\
\hline Antônio do A. Gurgel & & 1 légua de frente $\times 2$ de fundos \\
\hline Antônio do A. Gurgel & & $1 / 2$ légua de fundos \\
\hline Benedito de Oliveira Melo & 8 & năo registrada \\
\hline Benedito José Ferreira & 9 & $1 / 4$ légua de frente $\times 1 / 2$ de fundos \\
\hline Caetano Antônio Teixeira & 7 & 5 ou 6 léguas \\
\hline Bernardino Ant. da Silva e Sá & 5 & 1 légua em quadro \\
\hline Damasio Antunes de Lima & 11 & 2 léguas de extensăo \\
\hline Gertrudes Alves de Araujo & 14 & $1 / 4$ de légua de frente $x 1 / 2$ de fundos \\
\hline Gertrudes Alves de Araujo & & 600 braças frente $\times 600$ de fundos \\
\hline
\end{tabular}




\begin{tabular}{|c|c|c|}
\hline Proprietário & $N^{\bullet}$ Escravos & Tamanho Propriedade \\
\hline Henrique Paes de Farias & 10 & $1 / 2$ légua quadrada \\
\hline Henrique Paes de Farias & & não đimensionada \\
\hline Isabel Joaquina de Jesus & 12 & $1 / 4$ de légua de frente $\times 3 / 4$ de fundos \\
\hline José Tomás de Moura e Silva & 10 & $1 / 4$ de légua de frente $x 1$ de fundos \\
\hline José Moreira Branco & 11 & năo dimensionada \\
\hline José Coelho de Ávila & 17 & não discriminada \\
\hline Leandro Luís Vieira & 9 & 2 léguas em quadra \\
\hline Lourenço Waltrick & 12 & $11 / 2$ légua de frente $\times 2$ de fundos \\
\hline Luís José de Oliveira Ramos & $2^{*}$ & 2 léguas em quadro \\
\hline Manoel Cavalheiro Leitão & 9 & não discriminada \\
\hline Pedro da Silva Ribeiro & 9 & nāo discriminada \\
\hline Pedro da Silva Ribeiro & & não discriminada \\
\hline Venâncio José Antunes & 9 & $1 / 4$ légua de frente $x 1 / 2$ de fundos \\
\hline Venâncio José Antunes & & $1 / 4$ de légua de frente $x 1 / 2$ de fundos \\
\hline Venâncio José Antunes & & $1 / 4$ de légua de frente $x 1 / 2$ de fundos \\
\hline
\end{tabular}

- Anotado por se ter a matrícula dos seus escravos, em 1880, em número de dozel

A leitura atenta dos registros eclesiásticos de batizados, a partir da fundação da freguesia, confrontados com os dados disponíveis nos "Censos de Ordenanças", nos põe diante de uma população escrava com uma grande multiplicidade de proprietários (foram sumariados 391 proprietários de escravos!), anotados como não possuidores de terras ou, pelo menos, não relacioandos à propriedade fundiária!

\section{A matrícula de escravos e a abolição total}

A problemática da abolição gradual da escravidão relaciona-se amplamente com uma enorme massa de textos legais, a partir da abolição do tráfico negreiro.

O aceleramento da abolição gradual dar-se-á a partir da Lei $\mathrm{n}^{2}$ 1.507, de 26.09.1867, que o Ministério de Zacarias de Goes e Vasconcelos disciplina pelo Decreto $\mathrm{n}^{\circ} 4.129$, de 28.03 .1860 , baixado com o respectivo regulamento "para matrícula geral e arrecadação da taxa de escravos".

Em face de tais dispositivos legais far-se-ia a matrícula em julho e agosto de 1868 e ela seria efetuada em cada quinqüênio. ${ }^{13}$

A Lei do "Ventre Livre" (Lei n² 2.040, de 28.9.1871) estabelece, por sua vez, o critério da manumissão (resgate de escravos com os valores arrecadados, através da taxa da "meia siza", pelo comércio dos escravos), sempre apoiado na matrícula anual dos escravos, efetuada sob a supervisão de cada Junta de Classificação de escravos, existentes nos diferentes municípios. ${ }^{14}$ 
A Lei do "Ventre Livre", efetuada sob a égide do Ministério presidido pelo Visconde do Rio Branco, além de declarar "de condição livre os filhos de mulher escrava" criou um fundo especial destinado a resgatar, anualmente, certo número de escravos.

Assim, era efetuada, em cada município, a matrícula.

Somente, a 16 de maio de 1875, a Câmara Municipal de Lages, acusou à Presidência da Província, o recebimento do ofício-circular de 13 de maio daquele ano, recomendando sejam efetuados os trabalhos das "Juntas Classificadoras de Escravos". ${ }^{15}$

Já deveria ter sido efetuada, até aquele momento, a matrícula dos escravos existentes no município.

Em 1883, "Relatório" da Câmara Municipal de Lages à Presidência da Província, aponta na área de sua jurisdição, 950 escravos, divididos em três freguesias (a de Lages, a de São Joaquim e a de Baguaes!). ${ }^{16}$

Já, em 1887, a mesma Câmara Municipal encaminha à Presidência da Província uma "Descripção do Município de Lages", onde trata da população do município e afirma ser de " 557 escravos, segundo a nova matrícula". 17

Assim sendo, tem-se esta situação:

\begin{tabular}{lcc}
\hline Anos & $\begin{array}{c}\mathbf{N}^{\circ} \text { de Escravos } \\
\text { Matriculados }\end{array}$ & $\begin{array}{c}\mathbf{N}^{\circ} \text { de Escravos } \\
\text { Existentes* }\end{array}$ \\
\hline 1882 & - & 1.522 \\
1883 & 950 & 1.233 \\
1884 & - & 1.197 \\
1885 & - & - \\
1886 & - & 1.076 \\
1887 & 557 & 1.064 \\
\hline
\end{tabular}

- Dados de fontes oficiais diversas.

É importante salientar que a "matrícula" fora efetuada pelos proprietários em folhas avulsas (vide anexo).

Tem-se, desta forma, uma avaliação da escravidão nos "Campos de Lages".

\section{Conclusões}

Uma das maiores evidências deste estudo é o pequeno número de escravos em relação à propriedade fundiária, de pecuária extensiva.

De outra parte mostra quantos elementos elucidativos estão, ainda, à disposição do investigador da História da Escravidão no Brasil. 


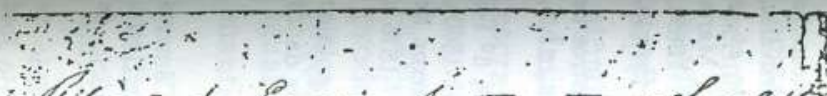

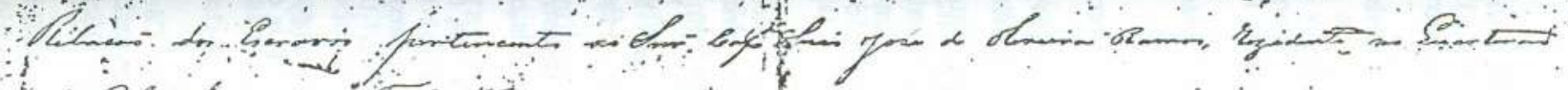

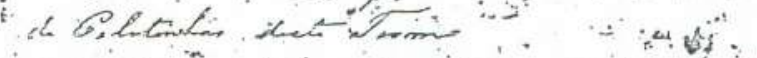

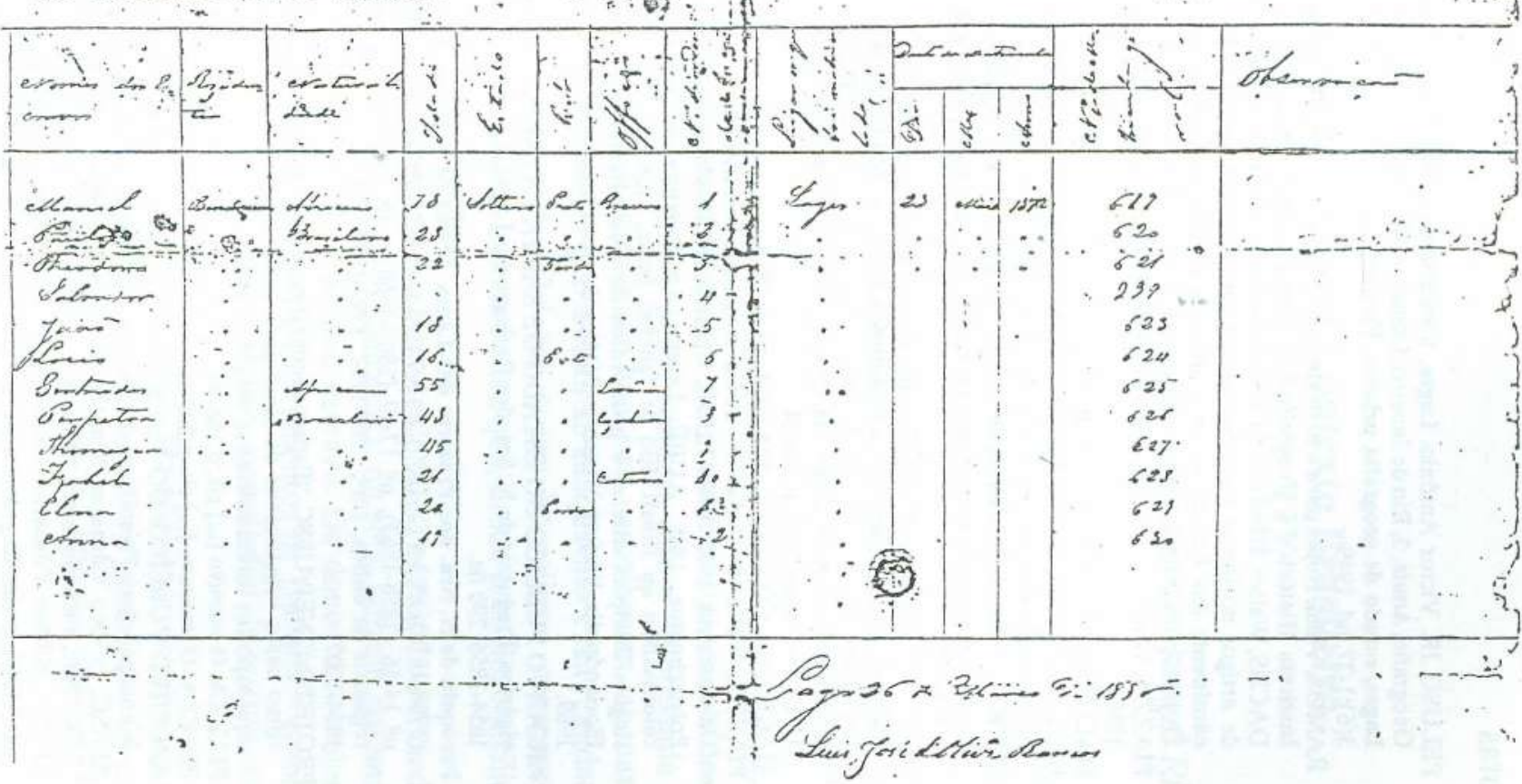

Tipo de Declaração para matrícula de escravos (Museu "Thiago de Castro", Lages, SC) 


\section{Notas}

1. PELUSO JR. Victor Antônio. Lages, a rainha da serra. X Congresso Brasileiro de Geografia, Anais, 3, Rio de Janeiro, Conselho Nacional de Geografia, 1952. p.33.; - . Lages, estudo de geografia urbana. Florianópolis, DEGC - Boletim Geográfico, 3(6):1-27, jul. 1949.

2. RAMOS, Vidal. Notas para a história da fundaçäo de Lages. Florianópolis, Revista do Instituto Histórico e Geográfico de Santa Catarina, v.12, p.13-45. 10 sem. 1944; DACHS, Waiter. Histórico da Vila de Nossa Senhora dos Prazeres das Lages. (série de artigos no jornal Guia Serrano, Lages, SC, 1962-1964); COSTA, Licurgo. 0 continente das Lagens - suas história e influência no sertão da terra firma. Florianópolis, Fundaçăo Catarinense de Cultura, 1982. 4v.

3. PIAZZA, Walter F. A colonizaçáo de Santa Catarina. 2.ed. Florianópolis, Lunardelli, 1988.

4. DACHS, cit.; COSTA, cit.; RAMOS, cit.

5. BELLOTTO, Heloisa Liberalli. Autoridade e confilito no Brasil colonial: o Governo do Morgado de Mateus. São Paulo, Secretaria de Estado da Cultura, 1979.

6. FERREIRA, Tito Lívio. Recenseamentos coloniais - Vila de Lages (1775-1794). Săo Paulo, Anais do Museu Paulista, tomo XIV (Imprensa Oficial do estado), 1950. p.383-451.

7. Os "Censos de Ordenanças" forma objetos de escritos de: FERREIRA, cit.; ALMEIDA, Luiz Castanho de. Povoamento de Lages. São Paulo, Revista Genealógica Brasileira, ano 5, $\mathrm{n}^{2} 10,2^{\circ} \mathrm{sem}$. 1944. p.395-400; MARCONDES, Benedito. Recenseamentos de Lages. São Paulo, Revista Genealógica Brasileira, ano 6, $\mathrm{n}^{\mathrm{e}}$ $11 / 12,1^{\circ}-2^{\circ}$ sem. 1945 , p. 203-24.

8. DACHS, cit.; COSTA, cit.; PIAZZA, cit. p. 78-9.

9. PIAZZA, Walter F. O escravo numa economia minifundiária. São Paulo, Resenha Universitária, 1975; VAN LEDE, Charles. De la colonisation au Brésil. Bruxelas, Polytechnique, 1845; AUBÉ, Léonce. La Province de Sainte-Catherine et la colonisation au Brésil. Rio đe Janeiro, Impr. Française, 1861; BOPPRÉ, Maria Regina. Eleições diretas e primórdios do coronelismo catarinense (1881-1889). Florianópolis, Projeto Memória Pública de Sta. Catarina n², Governo do Estado, 1989.

10. ARQUIVO PÚBLICO DO ESTADO DE SANTA CATARINA. Núcleo Registros de vigários. Freguesia de N. Sra. dos Prazeres das Lages. L.1, 1850-1857, 140 fls., e L.5, 1854-1856, $290 \mathrm{fls}$.

11. Paróquia de N. Sra. dos Prazeres das Lages. Livros de registros de batismos, $\mathrm{n}^{2} 1-2$ (1768-1818), n 3-4 (..-1830), n 5-7 (s/d.), n² 8-9 (1847-1851), n 10-13 (1852-1860), $\mathrm{n}^{2}$ 14-16 (1858-1863), $\mathrm{n}^{2} 17-19$ (1863-1868) e $\mathrm{n}^{2}$ 20-21 (1868-1872); e Livros de registros de óbitos, s/n², 1767-1797, 1799-1822, 1845-1855, 1855-1867, 1867-1876 e 1874-1907.

12 PROJETO FINEP/UFSC. "Espaço Geográfico, estrutura econômica e discurso político como bases constitutivas đa identidade catarinense". (Não concluído). (Os dados aqui expostos foram coletados em 1988/1989.)

13. PIAZZA. O escravo [...] cit. p.186-94.

14. PIAZZA. O jescravo [...] cit. p.200-6.

15. ARQUIVO PÚBLICO DO ESTADO DE SANTA CATARINA. Núcleo Câmaras Municipais para Presidência da Provincia. Offício de 16.5.1875, da Câmara de Lages.

16. APESC. Núcleo Câmaras Municipais para Presidência da Província. Ofício de 13.7.1883, encaminhando "Relatório" sobre situação do município.

17. APESC. Núcleo Câmaras Municipais para Presidência da Província. Ofício de 19.4.1887, assinado pelo Presidente da Câmara Municipal de Lages, Belisário José d'Oliveira Ramos, ao Presidente da Província, Dr. Francisco José da Rocha, encaminhando documento intitulado "Descripçăo do Munić́pio de Lages". 